\title{
Myocardial ischemia-reperfusion injury: a neglected therapeutic target
}

\author{
Derek J. Hausenloy and Derek M. Yellon
}

The Hatter Cardiovascular Institute, University College London, London, United Kingdom.

\begin{abstract}
Acute myocardial infarction (MI) is a major cause of death and disability worldwide. In patients with MI, the treatment of choice for reducing acute myocardial ischemic injury and limiting MI size is timely and effective myocardial reperfusion using either thombolytic therapy or primary percutaneous coronary intervention (PPCI). However, the process of reperfusion can itself induce cardiomyocyte death, known as myocardial reperfusion injury, for which there is still no effective therapy. A number of new therapeutic strategies currently under investigation for preventing myocardial reperfusion injury have the potential to improve clinical outcomes in patients with acute MI treated with PPCI.
\end{abstract}

\section{Introduction}

Coronary heart disease (CHD) is the leading cause of death and disability worldwide. According to the WHO, 7,254,000 deaths worldwide (12.8\% of all deaths) resulted from CHD in 2008. The effects of CHD are usually attributable to the detrimental effects of acute myocardial ischemia-reperfusion injury (IRI). IRI typically arises in patients presenting with an acute ST-segment elevation myocardial infarction (STEMI), in whom the most effective therapeutic intervention for reducing acute myocardial ischemic injury and limiting the size of myocardial infarction (MI) is timely and effective myocardial reperfusion using either thrombolytic therapy or primary percutaneous coronary intervention (PPCI). However, the process of myocardial reperfusion can itself induce further cardiomyocyte death, a phenomenon known as myocardial reperfusion injury (1-3). Although the process of myocardial reperfusion continues to improve with more timely and effective reperfusion and with advances in PCI technology and antiplatelet and antithrombotic agents for maintaining the patency of the infarct-related coronary artery, there is still no effective therapy for preventing myocardial reperfusion injury. In this respect, myocardial reperfusion injury remains a neglected therapeutic target for cardioprotection in PPCI patients. In this article, the pathophysiology of myocardial 1RI and the emerging therapeutic strategies for protecting the heart from its detrimental effects are reviewed.

\section{Pathophysiology of myocardial ischemic injury}

Acute occlusion of the coronary artery in the STEMI patient subjects the myocardium supplied by that vessel to acute myocardial ischemia, thereby demarcating the area at risk (AAR) of potential MI, should the acute coronary occlusion be sustained or permanent. If the period of acute myocardial ischemia is prolonged (more than 20 minutes) a "wave front" of cardiomyocyte death begins in the subendocardium and extends transmurally over time toward the epicardium (4).

The deprivation of oxygen and nutrient supply results in a series of abrupt biochemical and metabolic changes within the myocardium (Figure 1). The absence of oxygen halts oxidative phosphorylation, leading to mitochondrial membrane depolarization, ATP depletion, and inhibition of myocardial contractile

Conflict of interest: The authors have declared that no conflict of interest exists. Citation for this article: J Clin Invest. 2013;123(1):92-100. doi:10.1172/JCI62874. function. This process is exacerbated by the breakdown of any available ATP, as the $\mathrm{F}_{1} \mathrm{~F}_{0}$ ATPase functions in reverse to maintain the mitochondrial membrane potential, resulting in ATP hydrolysis and an increase in mitochondrial inorganic phosphate. In the absence of oxygen, cellular metabolism switches to anaerobic glycolysis, resulting in the accumulation of lactate, which reduces intracellular $\mathrm{pH}$ (to $<7.0$ ). The intracellular accumulation of protons activates the $\mathrm{Na}^{+}-\mathrm{H}^{+}$ion exchanger, which extrudes protons from the cell in exchange for $\mathrm{Na}^{+}$entry. The lack of ATP during ischemia ceases function of the $3 \mathrm{Na}^{+}-2 \mathrm{~K}^{+}$ATPase, thereby exacerbating the intracellular $\mathrm{Na}^{+}$overload. In response, the reverse activation of the $2 \mathrm{Na}^{+}-\mathrm{Ca}^{2+}$ ion exchanger results in intracellular $\mathrm{Ca}^{2+}$ overloading as the cell tries to extrude $\mathrm{Na}^{+}(5)$.

\section{Pathophysiology of myocardial reperfusion injury}

After the onset of acute myocardial ischemia in patients with STEMI, timely myocardial reperfusion using PPCI is essential to salvage viable myocardium, limit MI size, preserve LV systolic function, and prevent the onset of heart failure. However, the reperfusion of acutely ischemic myocardium can independently induce cardiomyocyte death (1-3), although this concept has been difficult to accept over the years. The four recognized forms of myocardial reperfusion injury are discussed in detail below, the first two reversible and the second two irreversible.

Reperfusion-induced arrbythmias. The sudden reperfusion of acutely ischemic myocardium in STEMI patients undergoing PPCI may be accompanied by ventricular arrhythmias, which usually selfterminate or are easily treated (6).

Myocardial stunning. The reversible post-ischemic contractile dysfunction that occurs on reperfusing acute ischemic myocardium is referred to as myocardial stunning. This form of reperfusion injury results from the detrimental effects of oxidative stress and intracellular calcium overload on the myocardial contractile apparatus (7).

Microvascular obstruction. Microvascular obstruction (MVO) was first described by Krug et al. in 1966 as the "inability to reperfuse a previously ischemic region" (8). The major contributing factors include capillary damage with impaired vasodilatation, external capillary compression by endothelial cell and cardiomyocyte swelling, micro-embolization of friable material released from the atherosclerotic plaque, platelet micro-thrombi, the release of soluble vasomotor and thrombogenic substances, and neutrophil 


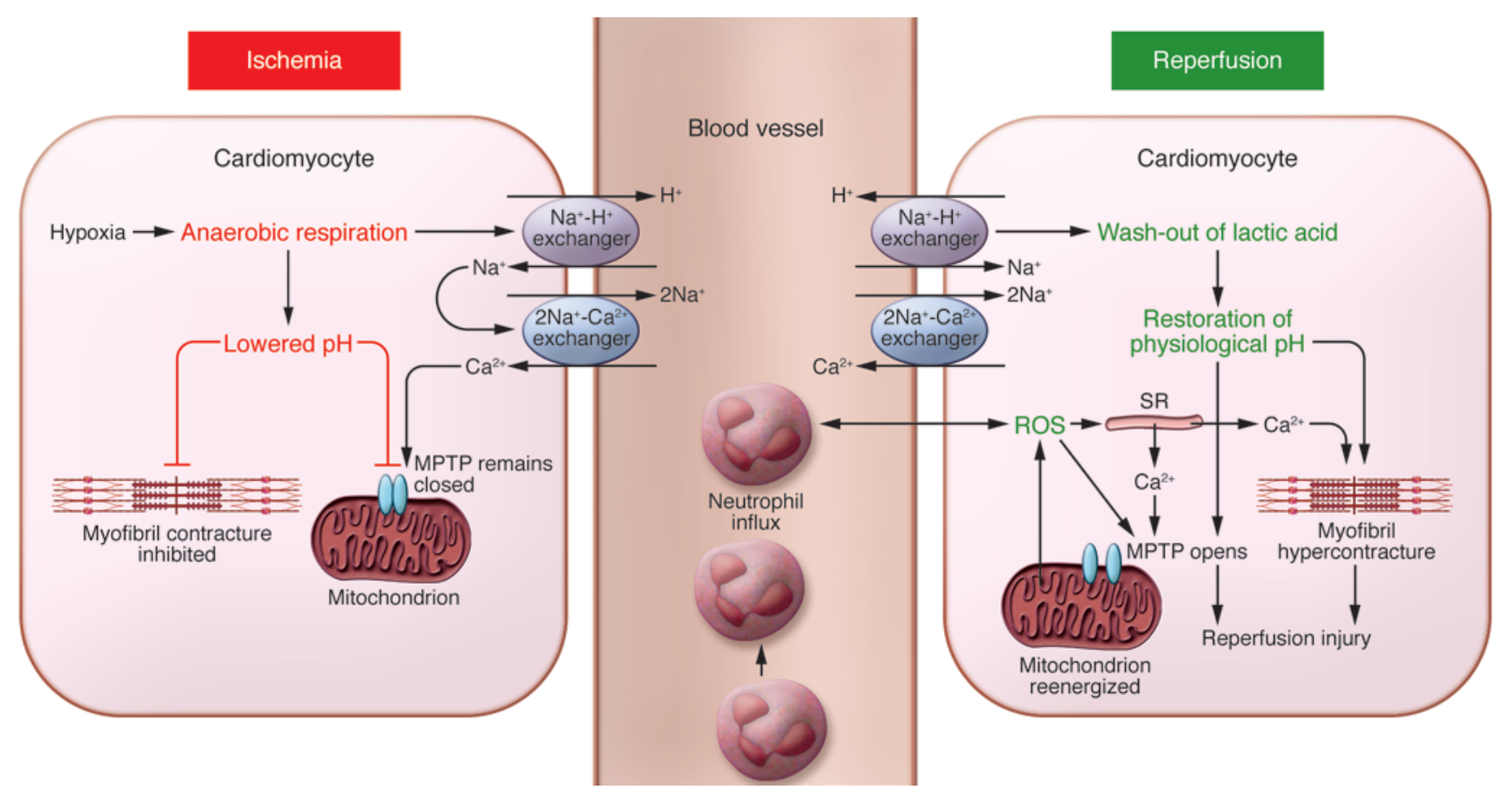

Figure 1

Schematic illustrating the main proponents of acute myocardial IRI. During acute myocardial ischemia, the absence of oxygen switches cell metabolism to anaerobic respiration, resulting in the production of lactate and a drop in intracellular $\mathrm{pH}$. This induces the $\mathrm{Na}^{+}-\mathrm{H}^{+}$exchanger to extrude $\mathrm{H}^{+}$and results in intracellular $\mathrm{Na}^{+}$overload, which activates the $2 \mathrm{Na}^{+}-\mathrm{Ca}^{2+}$ exchanger to function in reverse to extrude $\mathrm{Na}^{+}$and leads to intracellular $\mathrm{Ca}^{2+}$ overload. The $\mathrm{Na}^{+}-\mathrm{K}^{+}$ATPase ceases to function in ischemia, exacerbating intracellular $\mathrm{Na}^{+}$overload. The acidic conditions during ischemia prevent the opening of the MPTP and cardiomyocyte hypercontracture at this time. During reperfusion, the electron transport chain is reactivated, generating ROS. Other sources of ROS include xanthine oxidase (endothelial cells) and NADPH oxidase (neutrophils). ROS mediate myocardial reperfusion injury by inducing the opening of the MPTP, acting as a neutrophil chemoattractant, and mediating dysfunction of the sarcoplasmic reticulum (SR). This contributes to intracellular $\mathrm{Ca}^{2+}$ overload and damages the cell membrane by lipid peroxidation, inducing enzyme denaturation and causing direct oxidative damage to DNA. Reperfusion and reactivation of the $\mathrm{Na}^{+}-\mathrm{H}^{+}$exchanger result in washout of lactic acid, resulting in the rapid restoration of physiological $\mathrm{pH}$, which releases the inhibitory effect on MPTP opening and cardiomyocyte contracture. The restoration of the mitochondrial membrane potential drives calcium into the mitochondria, which can also induce MPTP opening. Several hours after the onset of myocardial reperfusion, neutrophils accumulate in the infarcted myocardial tissue in response to the release of the chemoattractants ROS, cytokines, and activated complement.

plugging (9-12). At coronary angiography in PPCI patients, MVO manifests as sluggish coronary blood flow, impaired myocardial blush grade, and a characteristic coronary flow velocity profile (13). Importantly, 30\%-40\% of PPCI patients in whom coronary blood flow in the infarct-related coronary artery appears normal on coronary angiography have evidence of MVO as detected by myocardial contrast echocardiography $(14,15)$, myocardial perfusion nuclear scanning (16), or contrast-enhanced cardiac MRI $(17,18)$. The presence of MVO is associated with a larger MI size, a lower LV ejection fraction, adverse LV remodelling, and worse clinical outcomes $(15,19,20)$. In severe cases of MVO in which there is significant damage to the endothelium, extravasation of blood into the interstitium can produce intramyocardial hemorrhage within the area of infarction, a feature that can also be detected by cardiac MRI (21). No effective therapy currently exists for reducing $\mathrm{MVO}$ in patients who have undergone PPCI. Whether MVO is actually an independent causative factor of reperfusion-induced cardiomyocyte death or is merely a biomarker of severe myocardial IRI remains unclear.

Lethal myocardial reperfusion injury. Reperfusion-induced death of cardiomyocytes that were viable at the end of the index isch- emic event is defined as lethal myocardial reperfusion injury (2). The major contributory factors are discussed below and include oxidative stress, calcium overload, mitochondrial permeability transition pore (MPTP) opening, and hypercontracture (3). The existence of lethal myocardial reperfusion injury has been inferred in both experimental MI models and in patients with STEMI by the observation that therapeutic interventions applied solely at the onset of myocardial reperfusion reduced MI size by $40 \%-50 \%$ (3). This observation suggests that lethal myocardial reperfusion injury may account for up to $50 \%$ of the final MI size. Lethal myocardial reperfusion injury attenuates the full benefits of myocardial reperfusion in terms of MI size reduction and thus represents an important target for cardioprotection in PPCI patients (see Figure 2). However, no effective therapy currently exists for reducing lethal myocardial reperfusion injury in patients who have undergone PPCI.

\section{Mediators of myocardial reperfusion injury}

Experimental studies have identified several critical factors that act in concert to mediate the detrimental effects of myocardial reperfusion injury (see Figure 1). 


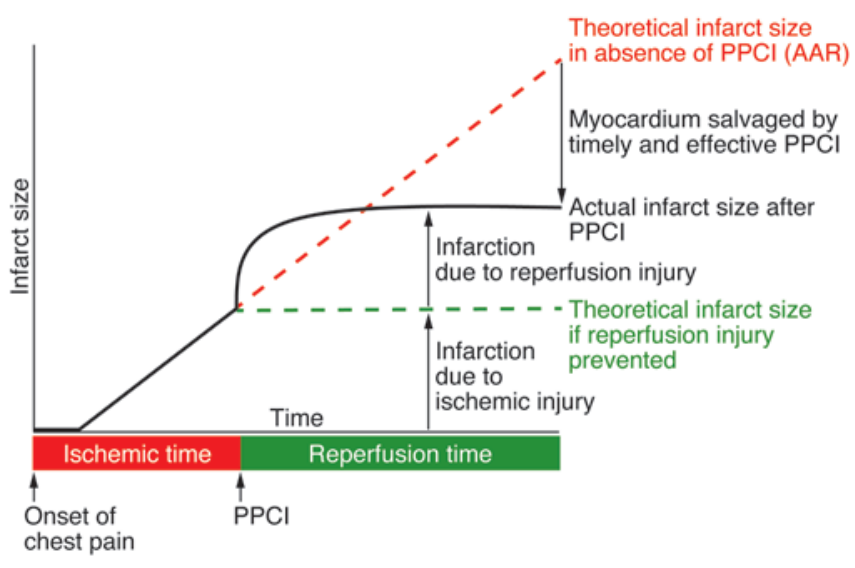

Figure 2

This figure illustrates the individual contributions of acute myocardial ischemic injury and myocardial reperfusion injury to final MI size (expressed in arbitrary units) in STEMI patients up to 24 hours following PPCI. The black solid line depicts the individual contributions to final MI size of acute myocardial ischemic injury and of myocardial reperfusion injury. The green dashed line depicts the theoretical MI size following PPCI based on acute myocardial ischemia alone in the absence of myocardial reperfusion injury. The red dashed line depicts the theoretical MI size based on acute myocardial ischemia alone in the absence of $\mathrm{PPCl}$. The presence of myocardial reperfusion injury attenuates the benefit of $\mathrm{PPCl}$ in terms of the reduction of $\mathrm{MI}$ size. Therefore, the administration of a therapeutic strategy as an adjunct to $\mathrm{PPCl}$ that is capable of reducing myocardial reperfusion injury would result in a smaller MI size (as depicted by the green dashed line) and take advantage of full benefits of myocardial reperfusion. Figure modified from Cardiovascular Research (93).

Oxidative stress. In the first few minutes of myocardial reperfusion, a burst of oxidative stress $(22,23)$ is produced by a variety of sources (Figure 1). This detrimental oxidative stress mediates myocardial injury and cardiomyocyte death through a number of different mechanisms (Figure 1). Based on these observations, antioxidant therapy was naturally considered to be an appropriate option to prevent such injury. However, both experimental and clinical studies have reported mixed results with the administration of antioxidant therapy at the onset of myocardial reperfusion. The reason for this may in part be due the inability of the antioxidant to enter the cell (24). In this regard, the discovery of mitochondrial-specific antioxidants may be more effective (25).

Intracellular $\mathrm{Ca}^{2+}$ overload. Intracellular and mitochondrial $\mathrm{Ca}^{2+}$ overload begins during acute myocardial ischemia and is exacerbated at the time of myocardial reperfusion due to disruption of the plasma membrane, oxidative stress-induced damage to the sarcoplasmic reticulum, and mitochondrial re-energization (Figure 1). Mitochondrial re-energization allows the recovery of the mitochondrial membrane potential that drives the entry of $\mathrm{Ca}^{2+}$ into mitochondria via the mitochondrial $\mathrm{Ca}^{2+}$ uniporter and subsequently induces the opening of the MPTP (Figure 1). Experimental studies have shown that pharmacologic antagonists of the sarcolemmal Ca ${ }^{2+}$ channel (26) or the mitochondrial $\mathrm{Ca}^{2+}$ uniporter (27), administered at the onset of myocardial reperfusion, reduce MI size by up to $50 \%$. However, not all experimental studies using this therapeutic strategy have been positive. Clinical studies of calcium channel blockers administered at the onset of myocardial reperfusion have not shown beneficial results (28). The recent identification of the mitochondrial $\mathrm{Ca}^{2+}$ uniporter (29) may result in the discovery of a new class of specific inhibitors for targeting lethal myocardial reperfusion injury.

The rapid restoration of physiological $p H$ at the time of reperfusion. During acute myocardial ischemia the intracellular $\mathrm{pH}$ decreases to less than 7.0, whereas at reperfusion, physiological $\mathrm{pH}$ is rapidly restored by the washout of lactate and the activation of the $\mathrm{Na}^{+}-\mathrm{H}^{+}$exchanger as well as the $\mathrm{Na}^{+}-\mathrm{HCO}^{-}$symporter. This $\mathrm{pH}$ shift contributes to the cardiomyocyte death of lethal myocardial reperfusion injury (30) by permitting MPTP opening and cardiomyocyte rigor hypercontracture in the first few minutes of reperfusion. Reperfusion of ischemic animal hearts with an acidic buffer can reduce MI size (31). Therefore, a potential treatment strategy for preventing lethal myocardial reperfusion injury would be to slow the normalization of physiologic $\mathrm{pH}$ at the time of myocardial reperfusion, which may be achieved via the pharmacologic inhibition of the $\mathrm{Na}^{+}-\mathrm{H}^{+}$exchanger (5) or by slowing the process of myocardial reperfusion, as in the case of ischemic postconditioning (IPost) (32), which has been termed "the $\mathrm{pH}$ hypothesis" by Cohen and Downey (33).

The MPTP: an important target for cardioprotection. Many of the above proponents of myocardial reperfusion injury appear to converge on the MPTP. The MPTP is a nonselective channel of the inner mitochondrial membrane, the opening of which results in mitochondrial membrane depolarization and uncoupling of oxidative phosphorylation, leading to ATP depletion and cell death $(34,35)$. In the setting of acute myocardial IRI, the MPTP has been shown to remain closed during ischemia and only open at reperfusion in response to mitochondrial $\mathrm{Ca}^{2+}$ and phosphate overload, oxidative stress and relative ATP depletion, and rapid $\mathrm{pH}$ correction (36). As such, preventing MPTP opening at the time of reperfusion by administering known MPTP inhibitors (such as the immunosuppressant cyclosporin A) at the onset of myocardial reperfusion has been reported in experimental studies to reduce MI size by $40 \%-50 \%$ in small and large animal MI models (37-40) and protect human atrial trabeculae subjected to simulated IRI (41). As such, the MPTP provides an important therapeutic target for preventing lethal myocardial reperfusion injury (see section below).

Inflammation: guilty mediator or innocent bystander. It is unclear whether the inflammatory response that accompanies an acute MI contributes to the pathogenesis of lethal myocardial reperfusion injury or whether it is a reaction to the acute myocardial injury (42). Although experimental studies have reported significant reduction of MI with therapeutic strategies designed to inhibit the inflammatory process at the time of myocardial reperfusion using antibodies against cell-adhesion molecules (43-45) and the inhibition of complement activation (46), corresponding clinical studies using this therapeutic approach have been largely negative (47-49).

Late myocardial reperfusion injury: extending the window of cardioprotection. The previously described stimulators of myocardial reperfusion injury all appear to operate in the first few minutes of myocardial reperfusion, providing a narrow window for reducing MI size in PPCI patients. However, several other important processes such as apoptosis and inflammation, which are also initiated during ischemia and continue over several hours into reperfusion, may contribute to the development of lethal myocardial reperfusion injury. These contributing pathways provide a potential second therapeutic window for reducing MI size, even well after myocardial reperfusion has taken place. Consistent with this proposal are 
Table 1

Mechanical therapeutic interventions for preventing myocardial reperfusion injury in patients undergoing PPCI

\begin{tabular}{|c|c|c|}
\hline $\begin{array}{l}\text { Study } \\
\text { IPost }\end{array}$ & N & Therapeutic intervention \\
\hline $\begin{array}{l}\text { Staat et al. } \\
2005(66)\end{array}$ & 30 & $\begin{array}{c}\text { Four 60-s cycles of low-pressure inflation/deflation } \\
\text { of angioplasty balloon }\end{array}$ \\
\hline $\begin{array}{l}\text { Thibault et al. } \\
2008 \text { (94) }\end{array}$ & 38 & $\begin{array}{l}\text { Four 60-s cycles of low-pressure inflation/deflation } \\
\text { of angioplasty balloon }\end{array}$ \\
\hline $\begin{array}{l}\text { Lonborg et al. } \\
2010 \text { (95) }\end{array}$ & 118 & $\begin{array}{l}\text { Four } 60 \text {-s cycles of low-pressure inflation/deflation } \\
\text { of angioplasty balloon }\end{array}$ \\
\hline $\begin{array}{l}\text { Sorensson et al. } \\
2010(96)\end{array}$ & 76 & $\begin{array}{c}\text { Four } 60 \text {-s cycles of low-pressure inflation/deflation } \\
\text { of angioplasty balloon }\end{array}$ \\
\hline
\end{tabular}

Tarantini et al. $78 \quad$ Four 60 -s cycles of low-pressure inflation/deflation of 2012 (97) angioplasty balloon; IPost protocol delivered in stent

Freixa et al. $\quad 79 \quad$ Four 60 -s cycles of low-pressure inflation/deflation of 2012 (98) angioplasty balloon; IPost protocol delivered in stent

Engstrom et al. 2,000 Four 30-s cycles of low-pressure inflation/deflation 2012 (99); $\quad$ of angioplasty balloon DANAMI-3

\section{RIC}

Botker et al $(77,100)$

Rentoukas et al. 92 2010 (101)

Therapeutic hypothermia
Gotberg et al. 20 2010 (102); RAPID-MI-ICE
Erlinge et al. 2012 (103); CHILL-MI

Therapeutic hyperoxemia

O’Neill et al. 269
2007 (78);
AMIHOT I
Stone et al. 281
2009 (104);
AMIHOT II

Four 5-min cycles of inflation/deflation of cuff placed on upper arm, in the ambulance Three 4-min cycles of inflation/deflation of cuff placed on upper arm, delivered at hospital prior to PPCl
Cooling to $35^{\circ} \mathrm{C}$ prior to PPCI by i.v. infusion of 1-2 liters of cold saline and cooling with Philips InnerCool RTx Endovascular System
Cooling to $35^{\circ} \mathrm{C}$ prior to $\mathrm{PPCl}$ by i.v. infusion of 1-2 liters of cold saline and cooling with Philips InnerCool RTx Endovascular System

IC hyperbaric hyperoxemic reperfusion

IC hyperbaric hyperoxemic reperfusion started after PPCl and continued for $90 \mathrm{~min}$ started after PPCl and continued for 90 min
Result

Reduction of MI size by $36 \%$ (72-hr AUC CK); improved myocardial blush grade

Reduction of MI size by $40 \%$ (72-hr AUC CK); reduction of

$\mathrm{MI}$ size by $39 \%$ at $6 \mathrm{mo}$, as assessed with SPECT;

$7 \%$ increase in EF, as assessed with ECG, at one year

Reduction of MI size by $19 \%$ at 3 mo, as assessed with CMR; $31 \%$ increase in myocardial salvage index

No difference in 48-hr AUC CK-MB or Trop-T; no difference in myocardial salvage, as assessed with CMR, on days

7-9; significant increase in myocardial salvage in patients with large AAR ( $>30 \%$ of LV)

Trend toward increased MI size; increased adverse events

Worse myocardial salvage; no difference in MI size

Ongoing phase 3 study investigating the effect of IPost on death and HHF

Increase in myocardial salvage index from 0.55 to 0.75 ; patients with anterior STEMI with occluded arteries showed most benefit Less STR and smaller Trop-I peak; additive effect with i.v. morphine

Reduction in MI size as \% of AAR, as assessed with CMR at 4 days ( $30 \%$ vs $48 \%)$; $43 \%$ reduction in peak and cumulative Trop-T release

Ongoing multicenter study investigating whether cooling prior to $\mathrm{PPCl}$ reduces $\mathrm{MI}$ size (as a \% of AAR) on CMR at 4 days

No difference in 14-day MI size as assessed with SPECT; patients with anterior STEMI $<6 \mathrm{~h}$ showed improvements ${ }^{A}$

No difference in 14-day MI size as assessed with SPECTA

APooled analysis of the results from AMIHOT I/II suggested beneficial effects on MI size. CMR, cardiac MRI; EF, ejection fraction; HHF, hospitalization for heart failure; STR, ST-segment resolution. CK, creatine kinase; CK-MB, CK (muscle and brain iso-enzyme); IC, intracoronary; Trop-T, troponin-T; Trop-I, troponin-I.

experimental data demonstrating an increase in MI size as reperfusion time progresses, suggesting a wave front of reperfusion injury that progress with time $(3,50,51)$. However, this is a controversial area of research, and some experimental studies have failed to demonstrate an increase in MI size with reperfusion time (52).

Several experimental studies have reported that administering cardioprotective agents such as erythropoietin (anti-apoptotic) (53), PI3K- $\gamma / \delta$ inhibitors (anti-inflammatory) (54), intracoronary aqueous oxygen (55), and IPost (anti-apoptotic and antiinflammatory) (56) from 30 minutes to 24 hours into myocardial reperfusion may still limit acute MI size at 72 hours. Whether this therapeutic window exists in patients with STEMI who are under- going PPCI is of great investigational interest, as such a window would allow a cardioprotective intervention to be administered some hours after the PPCI procedure. This area of research is still in its infancy but may suggest or provide an additional therapeutic window to target late into the reperfusion phase.

\section{Therapeutic strategies for reducing acute myocardial ischemic injury}

For patients presenting with a STEMI, the most effective and wellestablished therapeutic strategy for reducing acute myocardial ischemic injury and limiting MI size is timely myocardial reperfusion using either thrombolytic therapy or PPCI. The duration 


\section{Table 2}

Pharmacologic therapies for preventing myocardial reperfusion injury in PPCI patients

\begin{tabular}{|c|c|c|c|}
\hline $\begin{array}{l}\text { Study } \\
\text { Adenosine }\end{array}$ & $\mathbf{N}$ & Therapeutic intervention & Result \\
\hline $\begin{array}{l}\text { Ross et al. } 2005 \text { (105); } \\
\text { AMISTAD II } \\
\text { Anti-inflammatory agents }\end{array}$ & 2,118 & $\begin{array}{c}\text { Infusion of adenosine } 50 \text { or } 70 \mu \mathrm{g} / \mathrm{kg} / \mathrm{min} \\
\text { i.v. for } 3 \mathrm{~h} \text { after PPCl }\end{array}$ & $\begin{array}{l}\text { No difference in death or HHF at } 6 \text { months; post hoc analysis } \\
\text { showed benefits in patients presenting within } 3.2 \mathrm{~h}\end{array}$ \\
\hline $\begin{array}{l}\text { Armstrong et al. } \\
2007 \text { (72); } \\
\text { APEX-MI }\end{array}$ & 5,745 & $\begin{array}{l}\text { Pexelizumab } 2 \mathrm{mg} / \mathrm{kg} \text { i.v. bolus given over } \\
10 \mathrm{~min} \text { prior to PPCl, followed by } 0.05 \mathrm{mg} / \mathrm{kg} / \mathrm{h} \\
\text { infusion for } 24 \text { hours }\end{array}$ & No difference in deaths at 30 days (pexelizumab, $4.1 \%$; placebo, $3.9 \%$ ) \\
\hline $\begin{array}{l}\text { Atar et al. } \\
2009(49) \text {; } \\
\text { FIRE } \\
\text { Atrial natriuretic peptide }\end{array}$ & 232 & $\begin{array}{l}\text { Bolus of FX06 (200 mg i.v.) immediately } \\
\text { prior to guidewire crossing obstruction, } \\
\text { repeated within } 10 \mathrm{~min}\end{array}$ & $\begin{array}{l}\text { No difference in MI size at } 5 \text { days or } 4 \text { months, as assessed } \\
\text { with CMR; no difference in MI size, as assessed with Trop }\end{array}$ \\
\hline $\begin{array}{l}\text { Kitakaze et al. } 2007(106) \text {; } \\
\text { J-WIND } \\
\text { Atorvastatin }\end{array}$ & 569 & $\begin{array}{l}\text { Carperitide infusion at } 0.025 \mu \mathrm{g} / \mathrm{kg} / \mathrm{min} \text { i.v. } \\
\text { increase in LVEF at } 6-12 \text { months }\end{array}$ & $\begin{array}{l}\text { Reduction in MI size by } 14.7 \% \text { (total CK AUC); } \\
2.5 \% \text { increase in LVEF at } 6-12 \text { months }\end{array}$ \\
\hline $\begin{array}{l}\text { Kim et al. } \\
2010(107) ; \\
\text { STATIN STEMI }\end{array}$ & 171 & $\begin{array}{l}\text { Oral atorvastatin } 80 \mathrm{mg} \text { vs atorvastatin I } \\
\qquad 10 \mathrm{mg} \text { prior to PPC }\end{array}$ & $\begin{array}{c}\text { No effect on death, MI, or revascularization; no difference } \\
\text { in MI size (CK-MB maximum); improved myocardial } \\
\text { perfusion (blush grade, STR) }\end{array}$ \\
\hline $\begin{array}{l}\text { Hahn et al. } \\
\qquad 2011 \text { (108) }\end{array}$ & 173 & $\begin{array}{l}\text { Oral atorvastatin } 80 \mathrm{mg} \text { versus atorvastatin } \\
\text { no difference in perfusion }\end{array}$ & $\begin{array}{l}\text { No effect on MI size, as assessed with SPECT at days 5-14; } \\
\text { no difference in perfusion }\end{array}$ \\
\hline $\begin{array}{l}\text { Post et al. } 2012(109) \text {; } \\
\text { REPARATOR } \\
\text { CsA }\end{array}$ & 52 & $\begin{array}{l}\text { Oral atorvastatin } 80 \mathrm{mg} \text { versus atorvastatin } \\
\qquad 10 \mathrm{mg} \text { prior to } \mathrm{PPCl}\end{array}$ & $\begin{array}{l}\text { No effect on indexed LVESV; no difference in MI size or perfusion } \\
\text { size or perfusion }\end{array}$ \\
\hline $\begin{array}{l}\text { Piot et al. } 2008 \text { (80), } \\
\text { Mewton et al. } 2010 \text { (110) }\end{array}$ & 58 & CsA (2.5 mg/kg i.v.) 10 min prior to PPCI & $\begin{array}{l}\text { Reduction of } 44 \% \text { in MI size ( } 72-\mathrm{h} \text { AUC total CK); } \\
20 \% \text { reduction in MI size (as assessed with CMR in } \\
\text { a subset of } 27 \text { patients); } 28 \% \text { reduction in MI size } \\
\text { and smaller LVESV on CMR at } 6 \text { months }\end{array}$ \\
\hline $\begin{array}{l}\text { Ovize et al. } 2012 \text { (111); } \\
\text { CIRCUS }\end{array}$ & 972 & CsA (2.5 mg/kg i.v.) 10 min prior to $\mathrm{PPCl}$ & $\begin{array}{l}\text { Ongoing phase } 3 \text { clinical trial investigating whether CsA } \\
\text { improves clinical outcomes at one year (total mortality; } \\
\text { HHF; increase in LV end-diastolic volume }>15 \%\end{array}$ \\
\hline \multicolumn{4}{|r|}{ 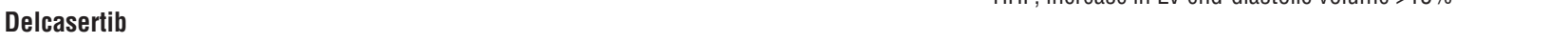 } \\
\hline $\begin{array}{l}\text { Lincoff et al. } 2011(112) ; \\
\text { PROTECTION-AMI } \\
\text { EPO }\end{array}$ & 1,083 & $\begin{array}{l}\text { Delcasertib at } 50,150 \text {, and } 450 \mathrm{mg} / \mathrm{h} \text { i.v. for } \\
24 \text { hours started prior to } \mathrm{PPCl}\end{array}$ & $\begin{array}{l}\text { No difference in infarct size as assessed with CK-MB AUC; } \\
\text { takes 5-30 min to reach steady state after beginning infusion }\end{array}$ \\
\hline $\begin{array}{l}\text { Voors et al. } \\
2010(113) \text {; } \\
\text { HEBE-III }\end{array}$ & 529 & $\begin{array}{l}\text { EPO epoetin- } \alpha 60,000 \text { IU i.v. within } \\
3 \text { hours after PPCI }\end{array}$ & $\begin{array}{l}\text { No difference in LVEF at } 6 \text { weeks; no difference in MI size } \\
\text { (as assessed using AUC CK-MB or Trop-T); more major } \\
\text { cardiac adverse events occurred with EPO }\end{array}$ \\
\hline $\begin{array}{l}\text { Ott et al. } \\
2010 \text { (114); } \\
\text { REVIVAL-3 }\end{array}$ & 138 & $\begin{array}{l}\text { EPO epoetin- } \beta 33,000 \text { IU i.v. immediately after PPCI, } \\
\text { repeated after } 24 \text { and } 48 \text { hours }\end{array}$ & $\begin{array}{c}\text { No difference in LVEF at } 6 \text { months, as assessed } \\
\text { with CMR; no difference in MI size (assessed with CMR } \\
\text { after } 5 \text { d and } 6 \text { mo) }\end{array}$ \\
\hline $\begin{array}{l}\text { Ludman et al. } \\
2011(115) \\
\text { Exenatide }\end{array}$ & 52 & $\begin{array}{l}\text { EPO epoetin- } \beta 50,000 \text { IU i.v. prior to PPCI, } \\
\text { repeated after } 24 \text { hours }\end{array}$ & $\begin{array}{l}\text { No difference in MI size at } 3 \text { days using CMR and Trop-T; } \\
\text { 2-fold higher incidence of MVO on CMR }\end{array}$ \\
\hline $\begin{array}{l}\text { Lonborg et al. } \\
\qquad 2011(81,116)\end{array}$ & 107 & $\begin{array}{l}\text { Infusion of exenatide ( } 25 \mathrm{mg} \text { in } 250 \mathrm{ml} \text { saline i.v.) } \\
\text { started } 15 \text { min prior to } \mathrm{PPCl} \text { and infused for } 6 \mathrm{~h}\end{array}$ & $\begin{array}{l}\text { Increase in myocardial salvage index at } 90 \text { days by CMR } \\
\text { ( } 0.71 \text { vs. } 0.62) \text {; reduced MI size as } \% \text { of AAR at } 90 \text { days as } \\
\text { assessed with CMR }(0.30 \text { vs. } 0.39) \text {; reduced MI size was } \\
\text { observed for patients presenting }<132 \text { min ( } 8 \% \text { vs } 11 \%)\end{array}$ \\
\hline \multicolumn{4}{|l|}{ GIK therapy } \\
\hline $\begin{array}{l}\text { Mehta et al. } 2005 \text { (117); } \\
\text { CREATE-ECLA }\end{array}$ & 20,201 & $\begin{array}{c}\text { Infusion of GIK (25\% glucose, } 50 \mathrm{U} / \mathrm{l} \text { insulin, } \\
80 \mathrm{mEq} / \mathrm{l} \mathrm{potassium} \mathrm{infused} \mathrm{i.v.} \mathrm{at} \\
1.5 \mathrm{ml} / \mathrm{kg} / \mathrm{h} \text { ) for } 24 \mathrm{~h}\end{array}$ & $\begin{array}{l}\text { No difference in } 30-d \text { mortality ( } 9.7 \% \text { placebo vs } 10.0 \% \text { GIK); } \\
\text { majority of patients were treated by thrombolysis and not PPCI; } \\
\text { GIK was begun after reperfusion in } 68 \% \text { of patients }\end{array}$ \\
\hline $\begin{array}{l}\text { Selke et al. } 2012(58) \text {; } \\
\quad \text { IMMEDIATE }\end{array}$ & 357 & $\begin{array}{l}\text { Infusion of GIK solution (i.v. for } 12 \mathrm{~h} \text { ), begun } \\
\text { in the ambulance for suspected STEMI patients }\end{array}$ & $\begin{array}{l}\text { No difference in progression to } \mathrm{MI} \text {, but reduction in } \\
\text { composite outcome of cardiac arrest or in-hospital } \\
\text { mortality was } 6.1 \% \text { with GIK vs } 14.4 \% \text { with placebo }\end{array}$ \\
\hline \multicolumn{4}{|l|}{ Sodium nitrite } \\
\hline $\begin{array}{l}\text { Frenneaux et al. } \\
2012 \text { (118); NIAMI }\end{array}$ & 200 & Sodium nitrite i.v. prior to $\mathrm{PPCl}$ & $\begin{array}{l}\text { Ongoing phase } 2 \text { trial to investigate whether i.v. sodium nitrite } \\
\text { reduces MI size (expressed as \% of the AAR on CMR) }\end{array}$ \\
\hline $\begin{array}{l}\text { Mathur et al. } 2012(119) \text {; } \\
\text { NITRITE-AMI } \\
\text { TR040303 }\end{array}$ & 80 & $\begin{array}{l}\text { Intracoronary bolus of sodium nitrite given } \\
\qquad 5 \text { min prior to } \mathrm{PPCl}\end{array}$ & $\begin{array}{c}\text { Ongoing phase } 2 \text { trial investigating whether intracoronary sodium } \\
\text { nitrite reduces MI size (48-h total AUC CK) }\end{array}$ \\
\hline $\begin{array}{l}\text { Atar et al. } 2012(120) \\
\quad \text { MitoCare }\end{array}$ & 180 & $\begin{array}{c}\text { Peripheral i.v. infusion of TR040303 } \\
\text { prior to PPCl }\end{array}$ & $\begin{array}{l}\text { Ongoing phase } 2 \text { trial investigating whether TR040303 } \\
\text { reduces MI size (72-h AUC CK and Trop-I) }\end{array}$ \\
\hline
\end{tabular}

CsA, cyclosporin A; EPO, erythropoietin; LVESV, LV end-systolic volume. 
of acute myocardial ischemia is a critical determinant of MI size, and as such, minimizing the time from chest pain onset to PPCI is the treatment priority. In the pre-hospital phase this includes increasing patient awareness of the symptoms of a MI (in order to minimize the delay before the emergency services are contacted), and the rapid diagnosis and transfer of STEMI patients to the PPCI center (57). At the hospital, reducing acute myocardial ischemic injury requires a treatment protocol that minimizes the door-to-PPCI time. In situations in which the transfer time to the PPCI center is prolonged, there is an opportunity for paramedics to administer a therapeutic strategy in the ambulance that can delay acute myocardial ischemic injury until PPCI has taken place. In this respect, the recently published IMMEDIATE clinical trial investigated the effects of metabolic modulation using an intravenous glucose insulin potassium (GIK) therapy administered in the ambulance to patients experiencing acute myocardial ischemia with suspected acute coronary syndrome. However, the study failed to find any difference in the primary endpoint of progression to acute MI, although patients with STEMI administered GIK therapy experienced less cardiac arrest and in-hospital mortality compared with those administered placebo (58).

\section{Therapeutic strategies for reducing myocardial reperfusion injury}

For patients presenting with a STEMI in whom acute myocardial ischemia has already taken place, the opportunity to intervene is limited to after the onset of myocardial ischemia or at the time of myocardial reperfusion (PPCI). The process of myocardial reperfusion by PPCI continues to be improved with earlier reperfusion, advances in PCI technology, and the introduction of more efficacious antiplatelet and antithrombotic agents for maintaining the patency of the infarct-related coronary artery. However, there remains no effective therapeutic agent for preventing either MVO or lethal myocardial reperfusion injury in patients with STEMI who are undergoing PPCI. Unfortunately, therapeutic targeting of the individual components of lethal myocardial reperfusion injury, including oxidative stress, calcium overload, $\mathrm{pH}$ correction, and, more recently, inflammation have produced disappointing results, the reasons for which are discussed below $(59,60)$.

However, a number of emerging therapeutic strategies for preventing lethal myocardial reperfusion injury have shown promise in small proof-of-concept clinical studies, and multicenter randomized clinical trials are currently underway to investigate the effects of these strategies on clinical outcomes in PPCI patients (Tables 1 And 2).

IPost. In contrast to unimpeded reperfusion, IPost is intermittent reperfusion of the acute ischemic myocardium, which has been reported to prevent myocardial reperfusion injury and reduce MI size by $40 \%-50 \%$ (61). It must be appreciated that IPost represents a form of modified reperfusion that was demonstrated in the 1980s to be beneficial in the form of gradual reperfusion (62-65). Staat et al. (66) first applied IPost to the clinical setting of PPCI: immediately after direct stenting, coronary blood reflow was allowed for 60 seconds, following which the angioplasty balloon was inflated upstream of the stent for 60 seconds to occlude coronary blood flow, and this cycle was repeated 4 times in total (Table 1). The results of this study confirmed the existence of lethal myocardial reperfusion injury in humans (67). A number of clinical studies have subsequently confirmed the beneficial effects of IPost, although not all studies have had positive results (Table 1). A large multicenter randomized clinical trial is now underway in Denmark (DANAMI-3) to investigate the effects of IPost on clinical outcomes in PPCI patients (Clinicaltrials.gov identifier NCT01435408).

Remote ischemic conditioning. IPost requires an invasive therapeutic intervention applied directly to the heart. However, the heart can be protected against acute IRI from a distance, by applying one or more cycles of brief, nonlethal ischemia and reperfusion to another organ or tissue, a phenomenon that has been termed remote ischemic conditioning (RIC) $(68,69)$. In the clinical setting, RIC has been achieved noninvasively by simply inflating and deflating a blood pressure cuff placed on the upper arm to induce three 5-minute cycles of ischemia and reperfusion $(70,71)$. This therapeutic approach has been reported to be beneficial in patients undergoing cardiac surgery (72-75) and in patients undergoing elective PCI (76). Most recently, Botker et al. (77) demonstrated that RIC applied by a paramedic to patients with STEMI in transit to the PPCI center improved myocardial salvage compared with control patients (Table 1). Again, the patients that benefited most from this therapeutic intervention were those presenting with an anterior STEMI and an occluded coronary artery (77). Whether RIC can actually improve clinical outcomes following PPCI is currently unknown.

Therapeutic byperoxemia and bypothermia. Two other mechanical interventions that have been reported in animal studies to be beneficial against myocardial reperfusion injury include therapeutic hyperoxemia (78) and hypothermia (79). Hyperbaric oxygen reduces MI size by decreasing tissue edema, reducing formation of lipid peroxide radicals, altering nitric oxide synthase expression, and inhibiting leukocyte adherence and plugging in the microcirculation. Lowering myocardial temperature during ischemia to $32^{\circ} \mathrm{C}-33^{\circ} \mathrm{C}$ can limit MI size in experimental studies by reducing metabolic demand, reducing the inflammatory response, decreasing platelet aggregation, and increasing myocardial efficiency. Proof-of-concept clinical studies in PPCI patients have demonstrated these therapeutic interventions to be potentially promising (Table 1).

Pharmacologic agents for preventing myocardial reperfusion injury. Elucidation of the mechanistic pathways underlying IPost have resulted in the identification of a number of new targets to prevent myocardial reperfusion injury. These include pharmacologic modulators of the reperfusion injury salvage kinase prosurvival pathway, such as adenosine, atrial natriuretic peptide, atorvastatin, erythropoietin, exenatide, delcasertib, and GIK (Table 2). Other agents are known to preserve mitochondrial function during acute IRI, such as cyclosporin A, sodium nitrite, and TRO40303 (Table 2). However, the results of clinical studies investigating these agents have been mixed, with the most promising pharmacologic agents being cyclosporin A (80) and exenatide (ref. 81 and Table 2).

\section{Cardiac MRI for assessing acute myocardial IRI}

Recent advances in cardiac magnetic resonance (CMR) imaging have made it possible to retrospectively assess several key features of acute myocardial IRI in patients with STEMI who have undergone PPCI treatment. Performing a CMR scan in the first week following PPCI allows the detection and the quantification of several important prognostic imaging biomarkers including MI size, $\mathrm{MVO}$, and intramyocardial hemorrhage (82). There is also the potential to measure myocardial salvage, with the AAR delineated by T2-weighted imaging of myocardial edema (83-85). However, this technique for measuring the AAR has its limitations and fur- 
ther study is required to validate its use (86-88). A repeat scan performed 4 to 6 months later provides an assessment of final MI size and post-MI LV remodeling in PPCI patients. Therefore, the availability of CMR allows the assessment of the efficacy of therapeutic strategies for preventing acute myocardial IRI and provides robust surrogate endpoints of cardioprotection for future clinical studies. However, it must be appreciated that surrogate endpoints to assess the efficacy of therapeutic interventions should be used to inform the design of larger, multicenter, randomized clinical trials with hard clinical endpoints.

\section{Improving translation of cardioprotection}

The research field of cardioprotection has been plagued by the large number of failed attempts to translate promising therapeutic strategies for preventing lethal myocardial reperfusion injury discovered in the basic science laboratory into the clinical setting. The reasons for this failure have been discussed in detail elsewhere $(59,60,89,90)$ and can be summarized as the use of inappropriate experimental animal models, the clinical testing of inconclusive therapies, and poor clinical trial design. Many experimental MI models fail to represent the clinical setting of an $\mathrm{MI}$ in terms of comorbidities (such as age, diabetes, dyslipidemia, and hypertension) and concomitant medication, the presence of which may interfere with the therapeutic cardioprotective intervention (91). The therapeutic intervention should confer conclusive cardioprotection in all experimental animal models tested before being investigated in the clinical setting. The National Heart, Lung, and Blood Institute (NHLBI) formed the CAESAR Consortium, a network of research centers in the United States (92) in which small and large animal models of experimental MI are used to investigate any promising cardioprotective strategies using an approach akin to a multicenter, randomized, controlled clinical trial. Finally, in terms of improving clinical study design, several recent strategy documents $(60,92)$ have suggested the following guidelines: only patients with anterior STEMI with complete occlusion of coronary flow and no collaterals should be included; the therapeutic intervention should be administered prior to myocardial reperfusion; and relevant endpoints pertinent to acute cardioprotection should be used.

\section{Conclusions}

Acute myocardial IRI is the major cause of the detrimental effects of CHD on the myocardium. This form of myocardial injury is characterized in STEMI patients who present with acute myocardial ischemia, in whom treatment priority is timely and effective myocardial reperfusion using either thrombolytic therapy or PPCI. Although improvements in myocardial reperfusion continue to take place in terms of new antiplatelet and antithrombotic agents, there is still no effective therapeutic strategy for preventing myocardial reperfusion injury. However, this is an active area of ongoing research, with the recent discovery of several mechanical and pharmacologic adjuncts to PPCI for preventing myocardial reperfusion injury. Multicenter, randomized clinical trials are now underway to investigate whether these emerging therapeutic strategies for reducing acute myocardial IRI can improve clinical outcomes in patients with CHD.

\section{Acknowledgments}

We thank the British Heart Foundation (program grant RG/03/007) for their ongoing funding and support. D.J. Hausenloy is funded by a British Heart Foundation Senior Clinical Research Fellowship (FS/06/023). This work was undertaken at the University College London Hospitals and University College London, which received a portion of funding from the Department of Health's National Institute for Health Research Biomedical Research Centres funding scheme.

Address correspondence to: Derek M. Yellon, Hatter Cardiovascular Institute, University College London, 67 Chenies Mews, London WC1E 6HX, United Kingdom. Phone: 44.203.447.9888; Fax: 44.203.447.5095; E-mail: d.yellon@ucl.ac.uk.
1. Braunwald E, Kloner RA. Myocardial reperfusion: a double-edged sword? J Clin Invest. 1985; 76(5):1713-1719.

2. Piper HM, Garcia-Dorado D, Ovize M. A fresh look at reperfusion injury. Cardiovasc Res. 1998; 38(2):291-300.

3. Yellon DM, Hausenloy DJ. Myocardial reperfusion injury. N Engl J Med. 2007;357(11):1121-1135.

4. Reimer KA, Lowe JE, Rasmussen MM, Jennings RB. The wavefront phenomenon of ischemic cell death. 1. Myocardial infarct size vs duration of coronary occlusion in dogs. Circulation. 1977;56(5):786-794.

5. Avkiran M, Marber MS. $\mathrm{Na}(+) / \mathrm{H}(+)$ exchange inhibitors for cardioprotective therapy: progress, problems and prospects. J Am Coll Cardiol. 2002; 39(5):747-753.

6. Hearse DJ, Tosaki A. Free radicals and reperfusioninduced arrhythmias: protection by spin trap agent PBN in the rat heart. Circ Res. 1987;60(3):375-383.

7. Kloner RA, Bolli R, Marban E, Reinlib L, Braunwald E. Medical and cellular implications of stunning, hibernation, and preconditioning: an NHLBI workshop. Circulation. 1998;97(18):1848-1867.

8. Krug A, Du Mesnil de Rochement R, Korb G. Blood supply of the myocardium after temporary coronary occlusion. Circ Res. 1966;19(1):57-62.

9. Ito H. No-reflow phenomenon and prognosis in patients with acute myocardial infarction. Nat Clin Pract Cardiovasc Med. 2006;3(9):499-506.

10. Luo AK, Wu KC. Imaging microvascular obstruction and its clinical significance following acute myocardial infarction. Heart Fail Rev. 2006; 11(4):305-312.

11. Heusch G, et al. Coronary microembolization: from bedside to bench and back to bedside. Circulation. 2009;120(18):1822-1836.

12. Kleinbongard $\mathrm{P}$, et al. Vasoconstrictor potential of coronary aspirate from patients undergoing stenting of saphenous vein aortocoronary bypass grafts and its pharmacological attenuation. Circ Res. 2011; 108(3):344-352.

13. Iwakura $\mathrm{K}$, et al. Alternation in the coronary blood flow velocity pattern in patients with no reflow and reperfused acute myocardial infarction. Circulation. 1996;94(6):1269-1275.

14. Ito $\mathrm{H}$, et al. Lack of myocardial perfusion immediately after successful thrombolysis. A predictor of poor recovery of left ventricular function in anterior myocardial infarction. Circulation. 1992; 85(5):1699-1705.

15. Ito H, et al. Clinical implications of the 'no reflow' phenomenon. A predictor of complications and left ventricular remodeling in reperfused anterior wall myocardial infarction. Circulation. 1996; 93(2):223-228.

16. Schofer J, Montz R, Mathey DG. Scintigraphic evidence of the "no reflow" phenomenon in human beings after coronary thrombolysis. J Am Coll Cardiol. 1985;5(3):593-598.

17. Bogaert J, Kalantzi M, Rademakers FE, Dymarkowski S, Janssens S. Determinants and impact of microvascular obstruction in successfully reper- fused ST-segment elevation myocardial infarction. Assessment by magnetic resonance imaging. Eur Radiol. 2007;17(10):2572-2580.

18. Lund GK, et al. Prediction of left ventricular remodeling and analysis of infarct resorption in patients with reperfused myocardial infarcts by using contrast-enhanced MR imaging. Radiology. 2007; 245(1):95-102.

19. Wu KC, et al. Prognostic significance of microvascular obstruction by magnetic resonance imaging in patients with acute myocardial infarction. Circulation. 1998;97(8):765-772.

20. Hombach V, et al. Sequelae of acute myocardial infarction regarding cardiac structure and function and their prognostic significance as assessed by magnetic resonance imaging. Eur Heart J. 2005; 26(6):549-557.

21. Ganame J, et al. Impact of myocardial haemorrhage on left ventricular function and remodelling in patients with reperfused acute myocardial infarction. Eur Heart J. 2009;30(12):1440-1449.

22. Hearse DJ, Humphrey SM, Chain EB. Abrupt reoxygenation of the anoxic potassium-arrested perfused rat heart: a study of myocardial enzyme release. J Mol Cell Cardiol. 1973;5(4):395-407.

23. Zweier JL, Flaherty JT, Weisfeldt ML. Direct measurement of free radical generation following reperfusion of ischemic myocardium. Proc Natl Acad Sci U S A. 1987;84(5):1404-1407.

24. [No authors listed]. Effect of 48-h intravenous trimetazidine on short- and long-term outcomes 
of patients with acute myocardial infarction, with and without thrombolytic therapy; A doubleblind, placebo-controlled, randomized trial. The EMIP-FR Group. European Myocardial Infarction Project--Free Radicals. Eur Heart J. 2000; 21(18):1537-1546.

25. Smith RA, Hartley RC, Murphy MP. Mitochondriatargeted small molecule therapeutics and probes. Antioxid Redox Signal. 2011;15(12):3021-3038.

26. Herzog WR, Vogel RA, Schlossberg ML, Edenbaum LR, Scott HJ, Serebruany VL. Short-term low dose intracoronary diltiazem administered at the onset of reperfusion reduces myocardial infarct size. Int J Cardiol. 1997;59(1):21-27.

27. Miyamae M, Camacho SA, Weiner MW, Figueredo $\mathrm{VM}$. Attenuation of postischemic reperfusion injury is related to prevention of $[\mathrm{Ca} 2+] \mathrm{m}$ overload in rat hearts. Am J Physiol. 1996;271(5 pt 2):H2145-H2153.

28. Bar FW, et al. Results of the first clinical study of adjunctive CAldaret (MCC-135) in patients undergoing primary percutaneous coronary intervention for ST-Elevation Myocardial Infarction: the randomized multicentre CASTEMI study. Eur Heart J. 2006;27(21):2516-2523.

29. De SD, Raffaello A, Teardo E, Szabo I, Rizzuto R. A forty-kilodalton protein of the inner membrane is the mitochondrial calcium uniporter. Nature. 2011; 476(7360):336-340.

30. Lemasters JJ, et al. The $\mathrm{pH}$ paradox in ischemiareperfusion injury to cardiac myocytes. EXS. 1996; 76:99-114.

31. Qian T, Nieminen AL, Herman B, Lemasters JJ. Mitochondrial permeability transition in $\mathrm{pH}$ dependent reperfusion injury to rat hepatocytes. Am J Physiol. 1997;273(6 pt 1):C1783-C1792.

32. Fujita $\mathrm{M}$, et al. Prolonged transient acidosis during early reperfusion contributes to the cardioprotective effects of postconditioning. Am J Physiol Heart Circ Physiol. 2007;292(4):H2004-H2008.

33. Cohen MV, Yang XM, Downey JM. The $\mathrm{pH}$ hypothesis of postconditioning: staccato reperfusion reintroduces oxygen and perpetuates myocardial acidosis. Circulation. 2007;115(14):1895-1903.

34. Hausenloy DJ, Yellon DM. The mitochondrial permeability transition pore: its fundamental role in mediating cell death during ischaemia and reperfusion. J Mol Cell Cardiol. 2003;35(4):339-341.

35. Heusch G, Boengler K, Schulz R. Inhibition of mitochondrial permeability transition pore opening: the Holy Grail of cardioprotection. Basic Res Cardiol. 2010;105(2):151-154.

36. Griffiths EJ, Halestrap AP. Mitochondrial nonspecific pores remain closed during cardiac ischaemia, but open upon reperfusion. Biochem J. 1995; 307(pt 1):93-98.

37. Hausenloy DJ, Maddock HL, Baxter GF, Yellon DM. Inhibiting mitochondrial permeability transition pore opening: a new paradigm for myocardial preconditioning? Cardiovasc Res. 2002;55(3):534-543.

38. Hausenloy DJ, Duchen MR, Yellon DM. Inhibiting mitochondrial permeability transition pore opening at reperfusion protects against ischaemia-reperfusion injury. Cardiovasc Res. 2003;60(3):617-625.

39. Argaud L, et al. Specific inhibition of the mitochondrial permeability transition prevents lethal reperfusion injury. J Mol Cell Cardiol. 2005;38(2):367-374.

40. Skyschally A, Schulz R, Heusch G. Cyclosporine A at reperfusion reduces infarct size in pigs. Cardiovasc Drugs Ther. 2010;24(1):85-87.

41. Shanmuganathan S, Hausenloy DJ, Duchen MR, Yellon DM. Mitochondrial permeability transition pore as a target for cardioprotection in the human heart. Am J Physiol Heart Circ Physiol. 2005; 289(1):H237-H242.

42. Vinten-Johansen J. Involvement of neutrophils in the pathogenesis of lethal myocardial reperfusion injury. Cardiovasc Res. 2004;61(3):481-497.

43. Hayward R, Campbell B, Shin YK, Scalia R, Lefer
AM. Recombinant soluble P-selectin glycoprotein ligand-1 protects against myocardial ischemic reperfusion injury in cats. Cardiovasc Res. 1999; 41(1):65-76.

44. Ma XL, Tsao PS, Lefer AM. Antibody to CD-18 exerts endothelial and cardiac protective effects in myocardial ischemia and reperfusion. J Clin Invest. 1991; 88(4):1237-1243

45. Zhao ZQ, Lefer DJ, Sato H, Hart KK, Jefforda PR, Vinten-Johansen J. Monoclonal antibody to ICAM-1 preserves postischemic blood flow and reduces infarct size after ischemia-reperfusion in rabbit. J Lenkoc Biol. 1997;62(3):292-300.

46. Vakeva AP, Agah A, Rollins SA, Matis LA, Li L, Stahl GL. Myocardial infarction and apoptosis after myocardial ischemia and reperfusion: role of the terminal complement components and inhibition by anti-C5 therapy. Circulation. 1998;97(22):2259-2267.

47. Granger CB, et al. Pexelizumab, an anti-C5 complement antibody, as adjunctive therapy to primary percutaneous coronary intervention in acute myocardial infarction: the COMplement inhibition in Myocardial infarction treated with Angioplasty (COMMA) trial. Circulation. 2003;108(10):1184-1190.

48. Armstrong PW, et al. Pexelizumab for acute STelevation myocardial infarction in patients undergoing primary percutaneous coronary intervention: a randomized controlled trial. JAMA. 2007; 297(1):43-51

49. Atar D, et al. Effect of intravenous FX06 as an adjunct to primary percutaneous coronary intervention for acute ST-segment elevation myocardial infarction results of the F.I.R.E. EFX. 2009; 53(8):720-729.

50. Rochitte CE, et al. Magnitude and time course of microvascular obstruction and tissue injury after acute myocardial infarction. Circulation. 1998; 98(10):1006-1014.

51. Zhao ZQ, et al. Dynamic progression of contractile and endothelial dysfunction and infarct extension in the late phase of reperfusion. J Surg Res. 2000; 94(2):133-144.

52. Ytrehus $\mathrm{K}$, et al. Rat and rabbit heart infarction: effects of anesthesia, perfusate, risk zone, and method of infarct sizing. Am J Physiol. 1994; 267(6 pt 2):H2383-H2390.

53. Gao E, Boucher M, Chuprun JK, Zhou RH, Eckhart AD, Koch WJ. Darbepoetin alfa, a long-acting erythropoietin analog, offers novel and delayed cardioprotection for the ischemic heart. Am J Physiol Heart Circ Physiol. 2007;293(1):H60-H68.

54. Doukas J, et al. Phosphoinositide 3-kinase gamma/ delta inhibition limits infarct size after myocardial ischemia/reperfusion injury. Proc Natl Acad Sci US A. 2006;103(52):19866-19871.

55. Spears JR, Prcevski P, Jiang A, Brereton GJ, Vander HR. Intracoronary aqueous oxygen perfusion, performed $24 \mathrm{~h}$ after the onset of postinfarction reperfusion, experimentally reduces infarct size and improves left ventricular function. Int J Cardiol. 2006;113(3):371-375.

56 . Roubille F, et al. Delayed postconditioning in the mouse heart in vivo. Circulation. 2011; 124(12):1330-1336.

57. Ornato JP. The ST-segment-elevation myocardial infarction chain of survival. Circulation. 2007; 116(1):6-9.

58. Selker HP, et al. Out-of-hospital administration of intravenous glucose-insulin-potassium in patients with suspected acute coronary syndromes: the IMMEDIATE randomized controlled trial. JAMA. 2012;307(18):1925-1933.

59. Ludman AJ, Yellon DM, Hausenloy DJ. Cardiac preconditioning for ischaemia: lost in translation. Dis Model Mech. 2010;3(1-2):35-38.

60 . Hausenloy DJ, et al. Translating novel strategies for cardioprotection: the Hatter Workshop Recommendations. Basic Res Cardiol. 2010;105(6):677-686.
61. Zhao ZQ, et al. Inhibition of myocardial injury by ischemic postconditioning during reperfusion: comparison with ischemic preconditioning. Am J Physiol Heart Circ Physiol. 2003;285(2):H579-H588.

62. Sato H, Jordan JE, Zhao ZQ, Sarvotham SS, Vinten-Johansen J. Gradual reperfusion reduces infarct size and endothelial injury but augments neutrophil accumulation. Ann Thorac Surg. 1997; 64(4):1099-1107.

63. Heusch G. Postconditioning: old wine in a new bottle? J Am Coll Cardiol. 2004;44(5):1111-1112.

64. Bopassa JC, Michel P, Gateau-Roesch O, Ovize M, Ferrera R. Low-pressure reperfusion alters mitochondrial permeability transition. Am J Physiol Heart Circ Physiol. 2005;288(6):H2750-H2755.

65. Musiolik J, et al. Reduction of infarct size by gentle reperfusion without activation of reperfusion injury salvage kinases in pigs. Cardiovasc Res. 2010; 85(1):110-117.

66. Staat $\mathrm{P}$, et al. Postconditioning the human heart. Circulation. 2005;112(14):2143-2148.

67. Yellon DM, Opie LH. Postconditioning for protection of the infarcting heart. Lancet. 2006; 367(9509):456-458.

68. Przyklenk K, Bauer B, Ovize M, Kloner RA, Whittaker P. Regional ischemic 'preconditioning' protects remote virgin myocardium from subsequent sustained coronary occlusion. Circulation. 1993; 87(3):893-899.

69. Hausenloy DJ, Yellon DM. Remote ischaemic preconditioning: underlying mechanisms and clinical application. Cardiovasc Res. 2008;79(3):377-386.

70. Kharbanda RK, et al. Transient limb ischemia induces remote ischemic preconditioning in vivo. Circulation. 2002;106(23):2881-2883.

71. Loukogeorgakis SP, et al. Transient limb ischemia induces remote preconditioning and remote postconditioning in humans by a K(ATP)-channel dependent mechanism. Circulation. 2007; 116(12):1386-1395

72. Cheung MM, et al. Randomized controlled trial of the effects of remote ischemic preconditioning on children undergoing cardiac surgery: first clinical application in humans. J Am Coll Cardiol. 2006; 47(11):2277-2282.

73. Hausenloy DJ, et al. Effect of remote ischaemic preconditioning on myocardial injury in patients undergoing coronary artery bypass graft surgery: a randomised controlled trial. Lancet. 2007; 370(9587):575-579.

74. Thielmann $\mathrm{M}$, et al. Remote ischemic preconditioning reduces myocardial injury after coronary artery bypass surgery with crystalloid cardioplegic arrest. Basic Res Cardiol. 2010;105(5):657-664.

75. Heusch G, Musiolik J, Kottenberg E, Peters J, Jakob $\mathrm{H}$, Thielmann M. STAT5 activation and cardioprotection by remote ischemic preconditioning in humans: short communication. Circ Res. 2012; 110(1):111-115

76. Hoole SP, et al. Cardiac Remote Ischemic Preconditioning in Coronary Stenting (CRISP Stent) Study: a prospective, randomized control trial. Circulation. 2009;119(6):820-827.

77. Botker HE, et al. Remote ischaemic conditioning before hospital admission, as a complement to angioplasty, and effect on myocardial salvage in patients with acute myocardial infarction: a randomised trial. Lancet. 2010;375(9716):727-734.

78. O'Neill WW, et al. Acute Myocardial Infarction with Hyperoxemic Therapy (AMIHOT): a prospective, randomized trial of intracoronary hyperoxemic reperfusion after percutaneous coronary intervention. J Am Coll Cardiol. 2007;50(5):397-405.

79. Duncker DJ, Klassen CL, Ishibashi Y, Herrlinger $\mathrm{SH}$, Pavek TJ, Bache RJ. Effect of temperature on myocardial infarction in swine. Am J Physiol. 1996; 270(4 Pt 2):H1189-H1199.

80. Piot C, et al. Effect of cyclosporine on reperfusion 
injury in acute myocardial infarction. $N$ Engl J Med. 2008;359(5):473-481

81. Lonborg J, et al. Exenatide reduces reperfusion injury in patients with ST-segment elevation myocardial infarction. Eur Heart J. 2012;33(12):1491-1499.

82. Perazzolo MM, Lima JA, Iliceto S. MRI in acute myocardial infarction. Eur Heart J. 2011;32(3):284-293.

83. Aletras $\mathrm{AH}$, et al. Retrospective determination of the area at risk for reperfused acute myocardial infarction with T2-weighted cardiac magnetic resonance imaging: histopathological and displacement encoding with stimulated echoes (DENSE) functional validations. Circulation. 2006; 113(15):1865-1870.

84. Friedrich MG, Abdel-Aty H, Taylor A, SchulzMenger J, Messroghli D, Dietz R. The salvaged area at risk in reperfused acute myocardial infarction as visualized by cardiovascular magnetic resonance. J Am Coll Cardiol. 2008;51(16):1581-1587.

85. Eitel I, et al. Prognostic significance and determinants of myocardial salvage assessed by cardiovascular magnetic resonance in acute reperfused myocardial infarction. J Am Coll Cardiol. 2010; 55(22):2470-2479

86. Mewton N, et al. Determination of the myocardial area at risk with pre-versus post-reperfusion imaging techniques in the pig model. Basic Res Cardiol. 2011;106(6):1247-1257.

87. Wince WB, Kim RJ. Molecular imaging: T2-weighted CMR of the area at risk--a risky business? Nat Rev Cardiol. 2010;7(10):547-549.

88. Heusch G. Reduction of infarct size by ischaemic post-conditioning in humans: fact or fiction? Eur Heart J. 2012;33(1):13-15.

89. Bolli R, Becker L, Gross G, Mentzer RJr, Balshaw D, Lathrop DA. Myocardial protection at a crossroads: the need for translation into clinical therapy. Circ Res. 2004;95(2):125-134.

90. Kloner RA, Rezkalla SH. Cardiac protection during acute myocardial infarction: where do we stand in 2004? J Am Coll Cardiol. 2004;44(2):276-286.

91. Ferdinandy P, Schulz R, Baxter GF. Interaction of cardiovascular risk factors with myocardial ischemia/reperfusion injury, preconditioning, and postconditioning. Pharmacol Rev. 2007;59(4):418-458.

92. Schwartz LL, et al. New horizons in cardioprotection: recommendations from the 2010 national heart, lung, and blood institute workshop. Circulation. 2011;124(10):1172-1179.

93. Ovize $\mathrm{M}$, et al. Postconditioning and protection from reperfusion injury: where do we stand? Position paper from the Working Group of Cellular Biology of the Heart of the European Society of Cardiology. Cardiovasc Res. 2010;87(3):406-423

94. Thibault $\mathrm{H}$, et al. Long-term benefit of postconditioning. Circulation. 2008;117(8):1037-1044.

95. Lonborg J, et al. Cardioprotective effects of ischemic postconditioning in patients treated with primary percutaneous coronary intervention, evalu- ated by magnetic resonance. Circ Cardiovasc Interv. 2010;3(1):34-41.

96. Sorensson P, et al. Effect of postconditioning on infarct size in patients with ST elevation myocardial infarction. Heart. 2010;96(21):1710-1715.

97. Tarantini G, et al. Postconditioning during coronary angioplasty in acute myocardial infarction: the POST-AMI trial [published online ahead of print April 9, 2012]. Int J Cardiol. doi:10.1016/j. ijcard.2012.03.136

98. Freixa X, et al. Ischaemic postconditioning revisited: lack of effects on infarct size following primary percutaneous coronary intervention. Eur Heart J. 2012; 33(1):103-112.

99. Engstrom T. DANish study of optimal acute treatment of patients with ST-elevation myocardial infarction (DANAMI-3). NIH Web site. http://clinicaltrials.gov/ct2/show/NCT01435408. Updated September 23, 2011. Accessed September 20, 2012.

100. Munk K, et al. Remote ischemic conditioning in patients with myocardial infarction treated with primary angioplasty: impact on left ventricular function assessed by comprehensive echocardiography and gated single-photon emission CT. Circ Cardiovasc Imaging. 2010;3(6):656-662.

101. Rentoukas I, et al. Cardioprotective role of remote ischemic periconditioning in primary percutaneous coronary intervention: enhancement by opioid action. JACC Cardiovasc Interv. 2010;3(1):49-55.

102. Gotberg $\mathrm{M}$, et al. A pilot study of rapid cooling by cold saline and endovascular cooling before reperfusion in patients with ST-elevation myocardial infarction. Circ Cardiovasc Interv. 2010;3(5):400-407.

103. Region Skane. Efficacy of endovascular catheter cooling combined with cold saline for the treatment of acute myocardial infarction (CHILL-MI). NIH Web site. http://clinicaltrials.gov/ct2/show/ NCT01379261. Updated August 9, 2012. Accessed September 20, 2012.

104.Stone GW, et al. Effect of supersaturated oxygen delivery on infarct size after percutaneous coronary intervention in acute myocardial infarction. Circ Cardiovasc Interv. 2009;2(5):366-375.

105.Ross AM, Gibbons RJ, Stone GW, Kloner RA Alexander RW. A randomized, double-blinded, placebo-controlled multicenter trial of adenosine as an adjunct to reperfusion in the treatment of acute myocardial infarction (AMISTAD-II). $J$ Am Coll Cardiol. 2005;45(11):1775-1780.

106. Kitakaze $\mathrm{M}$, et al. Human atrial natriuretic peptide and nicorandil as adjuncts to reperfusion treatment for acute myocardial infarction (J-WIND): two randomised trials. Lancet. 2007; 370(9597):1483-1493.

107. Kim JS, et al. Efficacy of high-dose atorvastatin loading before primary percutaneous coronary intervention in ST-segment elevation myocardial infarction: the STATIN STEMI trial. JACC Cardiovasc Interv. 2010;3(3):332-339.
108. Hahn JY, et al. Effects of atorvastatin pretreatment on infarct size in patients with ST-segment elevation myocardial infarction undergoing primary percutaneous coronary intervention. Am Heart J. 2011; 162(6):1026-1033.

109. Post S, et al. Early statin treatment prior to primary PCI for acute myocardial infarction: REPERATOR, a randomized placebo-controlled pilot trial. Catheter Cardiovasc Interv. 2012;80(5):756-765.

110. Mewton N, et al. Effect of cyclosporine on left ventricular remodeling after reperfused myocardial infarction. J Am Coll Cardiol. 2010;55(12):1200-1205.

111. Hospices Civils de Lyon. Cyclosporine and prognosis in acute myocardial infarction (MI) patients (CIRCUS). NIH Web site. http://clinicaltrials.gov/ ct2/show/NCT01502774. Updated December 29, 2011. Accessed September 20, 2012.

112.KAI Pharmaceuticals. Safety and efficacy study of KAI-9803 to treat subjects with ST elevation myocardial infarction [heart attack] (PROTECTION AMI). NIH Web site. http://clinicaltrials.gov/ct2/ show/NCT00785954. Updated August 30, 2011. Accessed September 20, 2012.

113. Voors AA, et al. A single dose of erythropoietin in ST-elevation myocardial infarction. Eur Heart J. 2010;31(21):2593-2600

114. Ott I, et al. Erythropoietin in patients with acute ST-segment elevation myocardial infarction undergoing primary percutaneous coronary intervention: a randomized, double-blind trial. Circ Cardiovasc Interv. 2010;3(5):408-413.

115.Ludman AJ, et al. Effect of erythropoietin as an adjunct to primary percutaneous coronary intervention: a randomised controlled clinical trial. Heart. 2011;97(19):1560-1565.

116. Lonborg J, et al. Exenatide reduces final infarct size in patients with ST-segment-elevation myocardial infarction and short-duration of ischemia. Circ Cardiovasc Interv. 2012;5(2):288-295.

117. Mehta SR, et al. Effect of glucose-insulin-potassium infusion on mortality in patients with acute ST-segment elevation myocardial infarction: the CREATE-ECLA randomized controlled trial. JAMA. 2005;293(4):437-446.

118. University of Aberdeen. Nitrites in acute myocardial infarction (NIAMI). NIH Web site. http://clinicaltrials.gov/ct2/show/NCT01388504. Updated April 15, 2012. Accessed September 20, 2012.

119. Barts $\&$ The London NHS Trust. Safety and effectiveness of intra-coronary nitrite in acute myocardial infarction (NITRITE-AMI). NIH Web site. http:// clinicaltrials.gov/ct2/show/NCT01584453. Updated April 24, 2012. Accessed September 20, 2012.

120. Trophos. Safety and efficacy study of TRO 40303 for reduction of reperfusion injury in patients undergoing percutaneous coronary intervention for acute myocardial infarction. NIH Web site. http://clinicaltrials.gov/ct2/show/NCT01374321. Updated June 5, 2012. Accessed September 20, 2012. 